Article

\title{
Photovoltaic Performance Enhancement of Silicon Solar Cells Based on Combined Ratios of Three Species of Europium-Doped Phosphors
}

\author{
Wen-Jeng Ho ${ }^{1, *} \mathbb{C}$, Bang-Jin You ${ }^{1}$, Jheng-Jie Liu ${ }^{1}$, Wen-Bin Bai ${ }^{1}$, Hong-Jhang Syu ${ }^{2}$ \\ and Ching-Fuh Lin ${ }^{2}$ \\ 1 Department of Electro-Optical Engineering, National Taipei University of Technology, No. 1, Section 3, \\ Zhongxial East Road, Taipei 10608, Taiwan; t105658002@ntut.edu.tw (B.-J.Y.); jjliu@mail.ntut.edu.tw (J.-J.L.); \\ t105658023@ntut.edu.tw (W.-B.B.) \\ 2 Graduate Institute of Photonics and Optoelectronics, National Taiwan University, No. 1, Section 4, \\ Roosevelt Road, Taipei 10617, Taiwan; f98941054@ntu.edu.tw (H.-J.S.); lincf@ntu.edu.tw (C.-F.L.) \\ * Correspondence: wjho@ntut.edu.tw; Tel.: +886-2-2771-2171 (ext. 4639)
}

Received: 27 April 2018; Accepted: 16 May 2018; Published: 18 May 2018

\begin{abstract}
This paper presents a scheme for the enhancement of silicon solar cells in terms of luminescent emission band and photovoltaic performance. The proposed devices are coated with an luminescent down-shifting (LDS) layer comprising three species of europium (Eu)-doped phosphors mixed within a silicate film $\left(\mathrm{SiO}_{2}\right)$ using a spin-on film deposition. The three species of phosphor were mixed at ratios of 0.5:1:1.5, 1:1:1, or 1.5:1:0.5 in weight percentage (wt \%). The total quantity of Eu-doped phosphors in the silicate solution was fixed at $3 \mathrm{wt} \%$. The emission wavelengths of the Eu-doped phosphors were as follows: $518 \mathrm{~nm}$ (specie-A), $551 \mathrm{~nm}$ (specie-B), and $609 \mathrm{~nm}$ (specie-C). We examined the extended luminescent emission bands via photoluminescence measurements at room temperature. Closely matching the luminescent emission band to the high responsivity band of the silicon semiconductor resulted in good photovoltaic performance. Impressive improvements in efficiency were observed in all three samples: 0.5:1:1.5 (20.43\%), 1:1:1 (19.67\%), 1.5:1:0.5 (16.81\%), compared to the control with a layer of pure $\mathrm{SiO}_{2}(13.80 \%)$.
\end{abstract}

Keywords: Eu-doped phosphors; luminescent down-shifting (LDS); photovoltaic performance; silicon solar cells; spin-on film

\section{Introduction}

Solar energy is among the most promising forms of renewable energy [1,2]. Currently, wafer-based crystalline silicon solar cells are the mainstay of the photovoltaic industry, with a market share of approximately $85 \%$ of the production of photovoltaic devices worldwide [3,4]. The theoretical maximum conversion efficiency of crystalline silicon solar cells with band-gap energy of $1.1 \mathrm{~V}$ is just $31 \%$, due to the effects of thermalisation [5], surface recombination [6,7], and spectral loss [8-11]. The conversion efficiency of crystalline silicon solar cells at ultraviolet-blue (UV-blue) wavelengths remains relatively low due to high surface recombination losses and low responsivity within the UV-blue wavelength band. Numerous methods have been devised to enhance conversion efficiency at short wavelengths, including the down-conversion (DC) or luminescent down-shifting (LDS) of the incident spectrum [12-17]. DC materials are able to convert high-energy incident photons into two or more photons of lower energy. The absorption of the resulting low-energy photons results in the generation of electron-hole pairs in the solar cell. This means that DC allows for the generation of more than one electron-hole pair from each high-energy photon. LDS has an effect similar to that of DC. 
However, only one photon is re-emitted from the luminescent converter. Europium-doped (Eu-doped) phosphors are ideally suited to LDS, due to their high quantum efficiency and large Stokes-shift $[18,19]$. In numerous studies, samples with single species of Eu-doped phosphors have been evaluated as an LDS material for photovoltaic devices [20-24]. However, few researchers have investigated combining multiple species of Eu-doped phosphors in various ratios [25,26].

In this study, we investigated silicon solar cells coated with an $\mathrm{LDS}$ layer comprising $\mathrm{SiO}_{2}$ with three species of Eu-doped phosphor in three weight percentages (wt \%). We then examined the LDS effect and luminescent emission band via photoluminescence (PL) measurements at room temperature. We also used optical reflectance and external quantum efficiency to evaluate the effectiveness of LDS. Finally, we quantified the efficiency enhancement of cells with and without the coating of Eu-doped phosphors using photovoltaic current density-voltage (J-V) measurements.

\section{Materials and Methods}

\subsection{Deposition and Characterization of LDS Layer Comprising Three Species of Eu-Doped Silicate Phosphor}

Three species of Eu-doped silicate phosphor (InteMatix Company product, Fremont, CA, USA) are used for LDS spectral conversion. The fluorescence emission wavelengths of those Eu-doped phosphors were as follows: $518 \mathrm{~nm}$ (specie-A), $551 \mathrm{~nm}$, (specie-B), and $609 \mathrm{~nm}$ (specie-C). The LDS layer was created by mixing Eu-doped phosphor powder in a silicate solution (Emulsitone Company product, Whippany, NJ, USA) and applying it via spin-on film deposition. Three LDS-layer samples were prepared with various combinations of the Eu-doped silicate phosphors, as follows: 1.5:1:0.5 (Sample-I), 1:1:1 (Sample-II), and 0.5:1:1.5 (Sample-III) in weight percentage (wt \%). The total quantity of Eu-doped phosphor material mixed in the silicate solution was fixed at $3 \mathrm{wt} \%$ in all samples. The mixed solutions were spin-coated on clean silicon substrates at $3000 \mathrm{rpm}$ for $60 \mathrm{~s}$ before being baked at $200{ }^{\circ} \mathrm{C}$ for $30 \mathrm{~min}$ under an air atmosphere. For comparison, we also fabricated samples with a $\mathrm{SiO}_{2}$ layer without Eu-doped phosphors using the same coating parameters. The surface morphology and chemical composition of the samples coated with Eu-doped phosphors LDS layer were examined using scanning electron microscopy and energy-dispersive X-ray spectroscopy (EDS; Hitachi S-4700, Hitachi High-Tech Fielding Corporation, Tokyo, Japan). The fluorescence emission band and LDS effects of the various samples (with single species or three species of Eu-doped phosphors) were examined via photoluminescence measurements (PL; Ramboss 500i Micro-PL Spectroscopy, DONGWOO Optron, Gyeonggi-Do, Korea) at room temperature using a solid-state UV laser with emission wavelength of $266 \mathrm{~nm}$ and emission power of $20 \mathrm{~mW}$ (MPL-F-266, Changchun New Industries Optoelectronics Technology Co., Ltd., Changchun, China) as a excitation source. The reflectance and light scattering effects of the silicate layer with and without Eu-doped phosphors particles was characterized using an UV-vis-NIR spectrophotometer (PerkinElmer LAMBDA 35, Waltham, MA, USA).

\subsection{Fabrication and Characterization of Silicon Solar Cell Coated with LDS Layer Comprising Three Species of Eu-Doped Silicate Phosphor}

Figure 1 presents schematic diagrams of silicon solar cells coated with $\mathrm{SiO}_{2}$ layer without Eu-doped phosphors and samples with an LDS layer of $\mathrm{SiO}_{2}$ with three species of Eu-doped silicate phosphor. A boron-doped crystalline silicon wafer with a thickness of $275 \mu \mathrm{m}$, (100) orientation, and resistivity of $10 \Omega$-cm was used as a starting material for the solar cell devices. After standard Radio Corporation of America (RCA) cleaning, an $\mathrm{n}^{+}$-Si emitter layer (300 nm-thick) was formed on the front-side of p-silicon via spin-on film processing using a liquid phosphorous source (Phosphorofilm, Emulsitone Co., Whippany, NJ, USA). The samples were then subjected to heat treatment in a rapid thermal annealing (RTA) chamber at $900{ }^{\circ} \mathrm{C}$ for 2 min under ambient $\mathrm{N}_{2}$. Following the formation of a diffuse $\mathrm{n}^{+}$-Si emitter layer, the phosphorous oxide remaining on the sample surface was etched using a buffered oxide etchant. Four-point probe resistivity and electrochemical capacitance-voltage profiling revealed that the $\mathrm{n}^{+}-\mathrm{Si}$ emitter layer had a sheet resistance of $50 \Omega$ /sq and a peak phosphorus 
concentration of $1020 \mathrm{~cm}^{-3}$ at the surface. The samples were then divided into individual cells of $4 \times 4 \mathrm{~mm}^{2}$ via isolation etching based on photolithography using a solution of $\mathrm{HNO}_{3}: \mathrm{HF}: \mathrm{H}_{2} \mathrm{O}$ at a ratio of 1:1:2. Ohmic contact electrodes were produced by depositing an aluminum (Al) film to a thickness of $300 \mathrm{~nm}$ on the back side and a titanium (Ti)/Al film (20-nm-Ti/300-nm-Al) on the front side using e-beam evaporation. After metallization processing, the samples underwent thermal annealing in an RTA chamber under ambient $\mathrm{N}_{2}$ at $450{ }^{\circ} \mathrm{C}$ for $20 \mathrm{~min}$ to ensure good ohmic contact between the metallic electrodes and Si semiconductor. This completed fabrication of bare silicon solar cells (bare cells).


Figure 1. Schematic diagram showing silicon solar cell coated with (a) 250-nm-thick $\mathrm{SiO}_{2}$ layer; (b) luminescent down-shifting (LDS) layer $\left(\mathrm{SiO}_{2}\right.$ layer comprising three species of Eu-doped silicate phosphors).

The external quantum efficiency (EQE; Enli Technology Co., Ltd., Kaohsiung City, Taiwan) response at wavelengths from $300 \mathrm{~nm}$ to $1100 \mathrm{~nm}$ was used to examine the LDS spectral conversion due to the multiple species of Eu-doped phosphor. Photovoltaic current density-voltage (J-V) measurements under one-sun air mass (AM) $1.5 \mathrm{G}$ simulation $\left(1000 \mathrm{~mW} / \mathrm{cm}^{2}\right.$ at $\left.25^{\circ} \mathrm{C}\right)$ were used to confirm the contribution of the LDS layer. The solar simulator (XES-151S, San-Ei Electric Co., Ltd., Osaka, Japan) was calibrated using a crystalline silicon reference cell (PVM-894, PV Measurements Inc., Boulder, CO, USA) certified by the National Renewable Energy Laboratory (NREL) prior to the measurement of devices.

\section{Results and Discussion}

Figure 2 presents the EDS spectra and fluorescence emission spectra of silicon samples coated with a $\mathrm{SiO}_{2}$ layer comprising single (a) specie-A, (b) specie-B, and (c) specie-C, of Eu-doped silicate phosphors. EDS is used for element analysis and the chemical characterization of solid samples. Each element within the sample has a unique atomic structure, which produces a unique set of peaks in its electromagnetic emission spectrum. In this study, specie-A was primarily composed of $\mathrm{O}, \mathrm{Si}$, $\mathrm{Ba}, \mathrm{Ti}$, and $\mathrm{Nb}$ with small quantities of $\mathrm{Eu}, \mathrm{Mn}$, and $\mathrm{Cl}$. Specie-B was primarily composed of $\mathrm{O}, \mathrm{Sr}$, $\mathrm{Si}, \mathrm{Ba}, \mathrm{Ti}$, and $\mathrm{Nb}$ with small quantities of $\mathrm{Mn}$ and $\mathrm{Eu}$. Specie-C was primarily composed of $\mathrm{O}, \mathrm{Sr}$, $\mathrm{Si}, \mathrm{Ba}$, and Ti with small quantities of $\mathrm{Eu}$ and $\mathrm{Mn}$. PL measurements at room temperature revealed the following fluorescence emission peaks: specie-A $(518.6 \mathrm{~nm})$, specie-B $(551.3 \mathrm{~nm})$, and specie-C $(609.1 \mathrm{~nm})$. In the next section, the PL results of samples with a single species of Eu-doped silicate phosphor are compared to samples with a combination of species in various concentration ratios. 

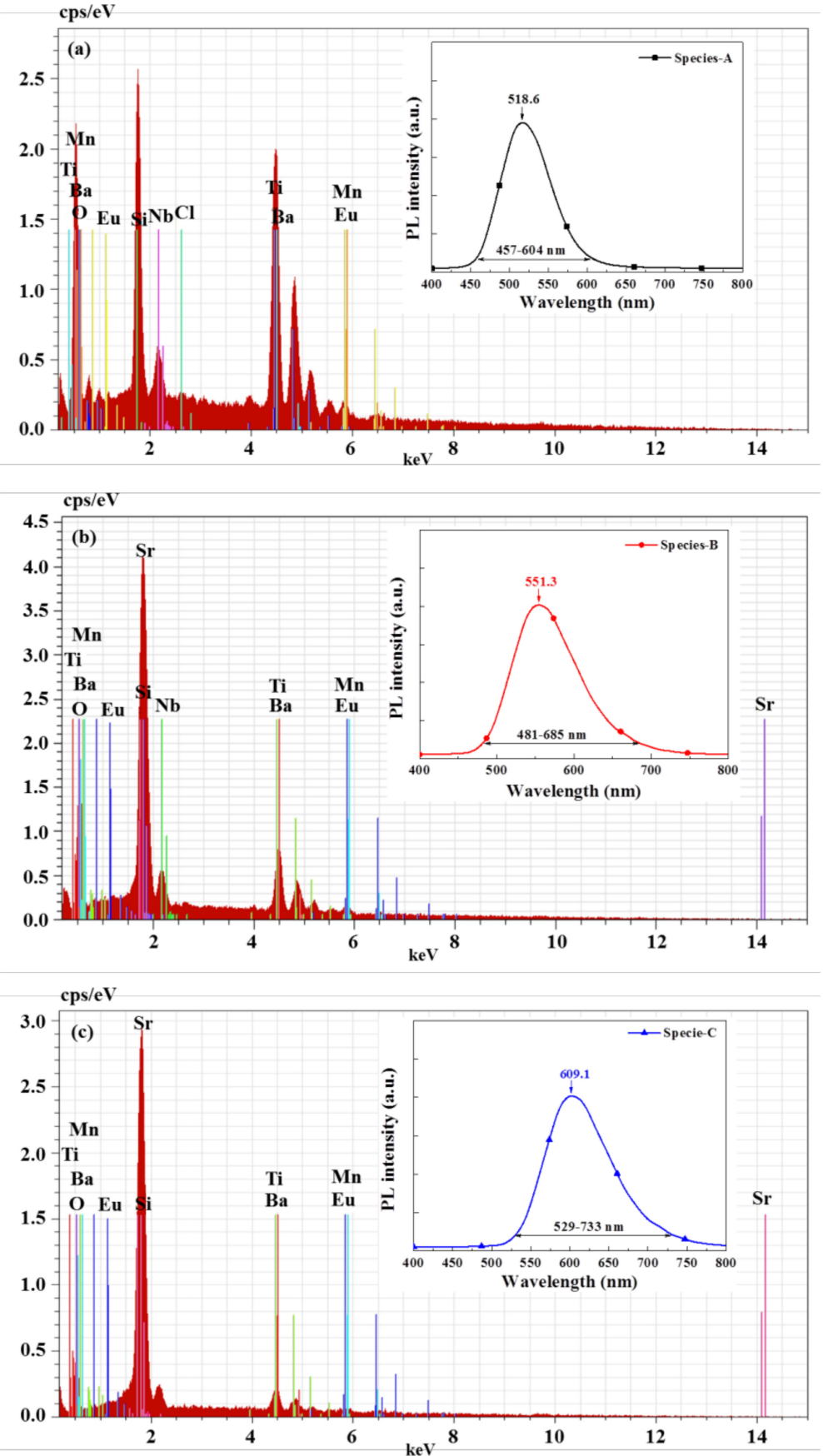

Figure 2. Energy-dispersive X-ray spectroscopy (EDS) spectra and fluorescence emission spectra of silicon samples coated with $\mathrm{SiO}_{2}$ layer comprising (a) specie-A; (b) specie-B; or (c) specie-C of Eu-doped silicate phosphors.

Figure 3 presents the PL emission spectra of the LDS layer containing a combination of specie-A/specie-B/specie-C Eu-doped phosphors at (A:B:C) concentration ratios of (a) 1.5:1:0.5, (b) 1:1:1, and (c) $0.5: 1: 1.5$ in wt \%. Figure 3 also plots the photo-responsivity of a bare silicon p-n junction device plotted for the sake of comparison. Table 1 lists the PL emission wavelength range, which is defined as the wavelength range at $10 \%$ of the maximum PL intensity corresponding to the responsivity values at these wavelength ranges. Figure 3a presents the band emission featuring a peak at $518.4 \mathrm{~nm}$ and a shoulder at approximately $580 \mathrm{~nm}$ in the sample with a phosphor combination of 1.5:1:0.5 in wt \%. Figure $3 \mathrm{~b}$ presents flat-band emission between 525 and $600 \mathrm{~nm}$ in the sample with a 
phosphor combination of 1:1:1. Figure $3 \mathrm{c}$ presents a similar band emission featuring a peak at $601.4 \mathrm{~nm}$ and a shoulder at approximately $540 \mathrm{~nm}$ in the sample with a phosphor combination of 0.5:1:1.5. The emission band of the LDS layer with a combination of three Eu-doped phosphor species was wider than that of the LDS layer with a single species. A wide emission band from the LDS layer with a combination of three Eu-doped phosphor species is highly beneficial to the re-emission of photons across a broad range of wavelengths for coupling with the active region of photovoltaic devices. The luminescent emission band of 1:1:1 and 0.5:1:1.5 samples extended into the high responsivity band of the silicon semiconductor. Thus, the wavelength of photons re-emitted from the 0.5:1:1.5 LDS layer approached a far higher responsivity region $(0.28-0.52 \mathrm{~A} / \mathrm{W})$ and this responsivity region was higher than that of 0.24-0.25 A/W (1:1:1 LDS layer) and 0.23-0.49 A/W (1.5:1:0.5 LDS layer), thereby enhancing the conversion efficiency of the silicon solar cells. The broadband LDS performance of the cells was also confirmed using EQE and photovoltaic J-V measurements.

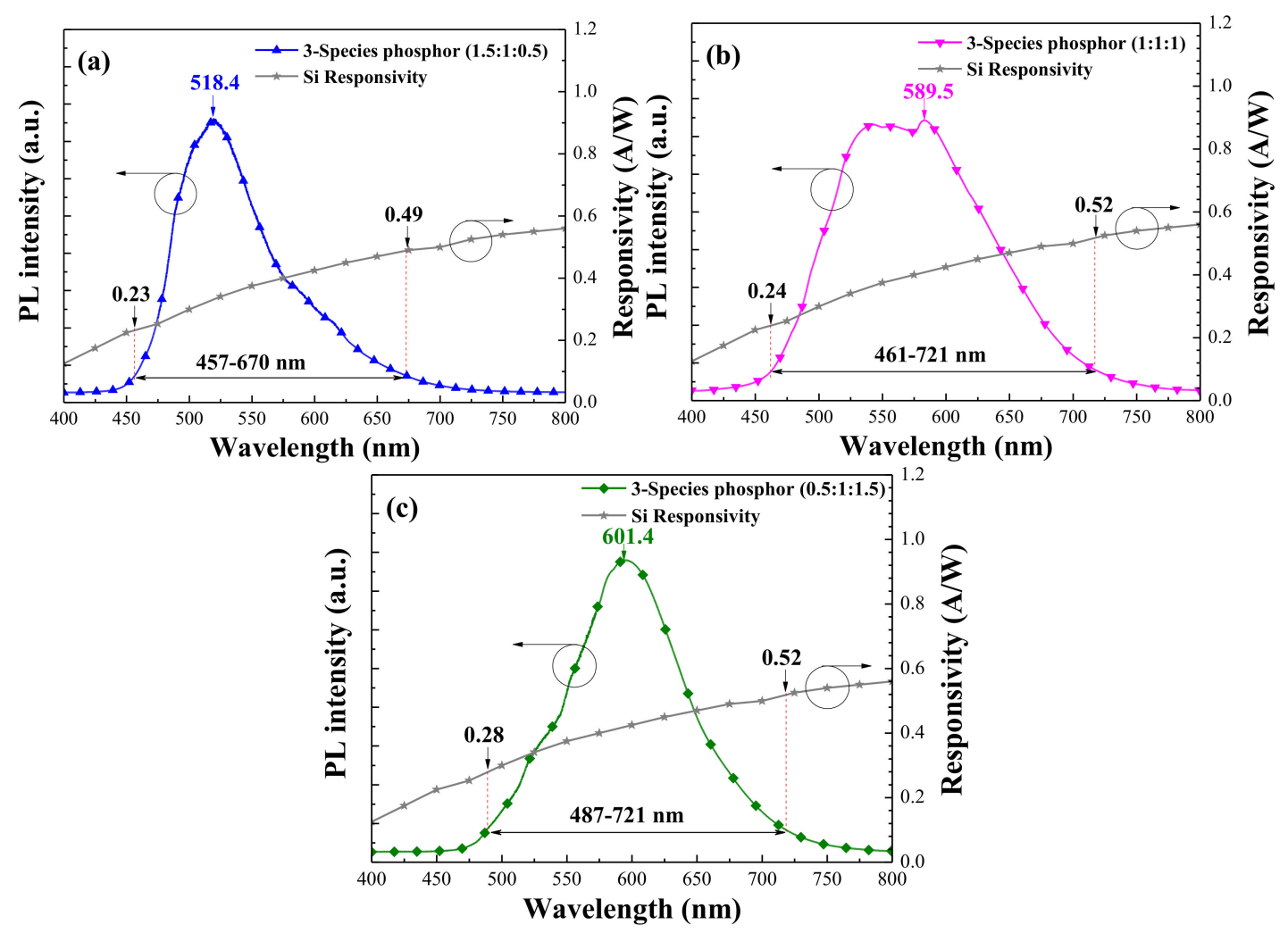

Figure 3. Photoluminescence (PL) emission spectra of LDS layer that included combinations of specie-A/specie-B/specie-C Eu-doped phosphors at (A:B:C) concentration ratios of (a) 1.5:1:0.5 (b) 1:1:1, and (c) $0.5: 1: 1.5$ in wt \%.

Table 1. Emission peaks, emission wavelength range at $10 \%$ of maximum PL intensity, and responsivity at the emission wavelength range of $10 \%$ of maximum PL intensity in all samples.

\begin{tabular}{cccc}
\hline $\begin{array}{c}\text { Combination of Eu-Doped } \\
\text { Phosphors }\end{array}$ & PL Emission Peak (nm) & $\begin{array}{c}\text { PL Emission Wavelength Range } \\
\text { (nm) @ 10\% of Max. Intensity }\end{array}$ & $\begin{array}{c}\text { Responsivity (A/W) Range @ } \\
\text { 10\% of Max. Intensity }\end{array}$ \\
\hline Specie-A & 518.6 & $457-604$ & $0.23-0.43$ \\
Specie-B & 551.3 & $481-685$ & $0.26-0.49$ \\
Specie-C & 609.1 & $529-733$ & $0.34-0.52$ \\
3-species phosphor (1.5:1:0.5) & 518.4 & $457-670$ & $0.23-0.49$ \\
3-species phosphor (1:1:1) & 589.5 & $461-721$ & $0.24-0.52$ \\
3-species phosphor (0.5:1:1.5) & 601.4 & $487-721$ & $0.28-0.52$ \\
\hline
\end{tabular}


Figure $4 \mathrm{a}, \mathrm{b}$ present optical microscope images $(100 \times)$ of LDS layers with (a) a single species (specie-A, in $3 \mathrm{wt} \%$ ) and (b) a combination of specie-A/specie-B/specie-C at a concentration ratio of 1:1:1 in wt $\%$ under excitation by a 405-nm semiconductor laser. The intensity and color of photons re-emitted from the LDS layer can be clear observed. Figure $4 \mathrm{c}$, d present the size distribution and coverage of the phosphor particles, which were, respectively, calculated using Image-J software from the images in Figure 4a,b. The phosphor particles had an average diameter of approximately $16 \mu \mathrm{m}$ and a coverage of approximately $13 \%$.
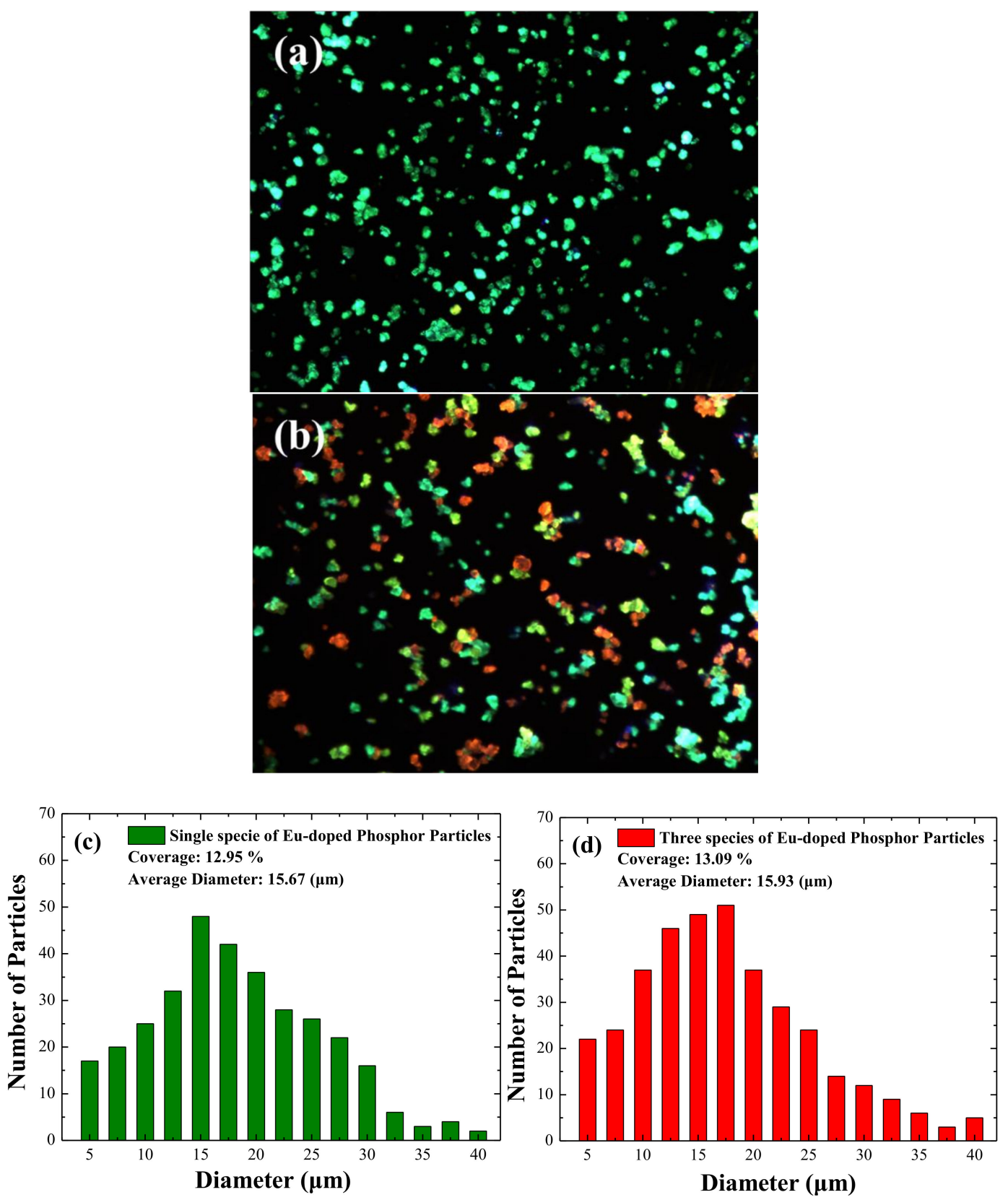

Figure 4. Optical microscope images $(100 \times)$ of LDS layer with (a) single species (specie-A); (b) combination of specie-A/specie-B/specie-C; (c,d) size distribution and coverage of phosphor particles respectively calculated using Image-J software from images in Figure $4 \mathrm{a}, \mathrm{b}$.

Figure 5 presents the reflective spectra of the bare silicon solar cell, a cell coated with a 250-nm thick layer of $\mathrm{SiO}_{2}$, and cells coated with a $\mathrm{SiO}_{2}$ layer containing three species of Eu-doped phosphors at concentration ratios of 0.5:1:1.5, or 1:1:1, or 1.5:1:0.5 (wt \%). The cell with a 250-nm thick $\mathrm{SiO}_{2}$ layer 
exhibited typical reflective characteristics, with lowest minimum reflectance of 19\% at approximately $550 \mathrm{~nm}$, due to destructive interference at the air $/ \mathrm{SiO}_{2}$ and $\mathrm{SiO}_{2} / \mathrm{Si}$ interfaces. The reflectance of the cells coated with a $\mathrm{SiO}_{2}$ layer comprising Eu-doped phosphors was notably lower than that of the bare silicon solar cell at wavelengths from 350 to $1000 \mathrm{~nm}$. The reflectance of the cells with Eu-doped phosphors was lower than that of cells with only a $\mathrm{SiO}_{2}$ layer (without Eu-doped phosphors) at a wavelength range of 350-500 $\mathrm{nm}$ and beyond $650 \mathrm{~nm}$. The reduction in reflectance at 350-500 nm can be attributed to the absorption of incident photons by Eu-doped phosphors, whereas the effects beyond $650 \mathrm{~nm}$ can be attributed to the forward scattering of incident photons by phosphor particles on the surface. As shown in the inset in Figure 5, the reflectance between 500 and $625 \mathrm{~nm}$ was slightly higher due in part to the re-emission of photons from the Eu-doped phosphors and the less than ideal antireflection characteristics caused by non-uniformity in the thickness of the $\mathrm{SiO}_{2}$ layer because phosphor particles dispersed in the $\mathrm{SiO}_{2}$ layer. The inset in Figure 5 also reveals the increase in reflectance due to the re-emission of photons from the Eu-doped phosphors and the location of peak reflection values between wavelengths of 500 and $625 \mathrm{~nm}$ associated with the weight percentage of the phosphors. The LDS layers with wt \% of 0.5:1:1.5 and 1.5:1:0.5 presented peak reflective wavelengths at 610 and $510 \mathrm{~nm}$, which is in good agreement with the PL results. We also calculated the average weighted reflectance $\left(R_{W}\right)$ of all samples at wavelengths $(\lambda)$ from 380 to $450 \mathrm{~nm}$ and from 380 to $1000 \mathrm{~nm}$ using Equation (1).

$$
R_{w}=\frac{\int_{\lambda_{\min }}^{\lambda_{\max }} R(\lambda) \cdot \phi_{p h}(\lambda) d \lambda}{\int_{\lambda_{\min }}^{\lambda_{\max }} \phi_{p h}(\lambda) d \lambda}
$$

where $R(\lambda)$ is reflectance as a function of wavelength and $\phi_{p h}(\lambda)$ is the photon flux of AM $1.5 \mathrm{G}$ solar energy spectrum as a function of wavelength. The resulting $R_{W}$ values are listed in Table 2 . These results demonstrate that the average weighted reflectance of cells with Eu-doped phosphors was lower than that of cells with only a $\mathrm{SiO}_{2}$ layer (without Eu-doped phosphors) at a wavelength range of 380-450 $\mathrm{nm}$ and 380-1000 nm due to the effects of absorption and the forward scattering of incident photons by phosphor particles. The reduction of reflectance due to the $\mathrm{SiO}_{2}$ layer and the differently phosphor containing $\mathrm{SiO}_{2}$ layers would be correlated with the EQE increase.

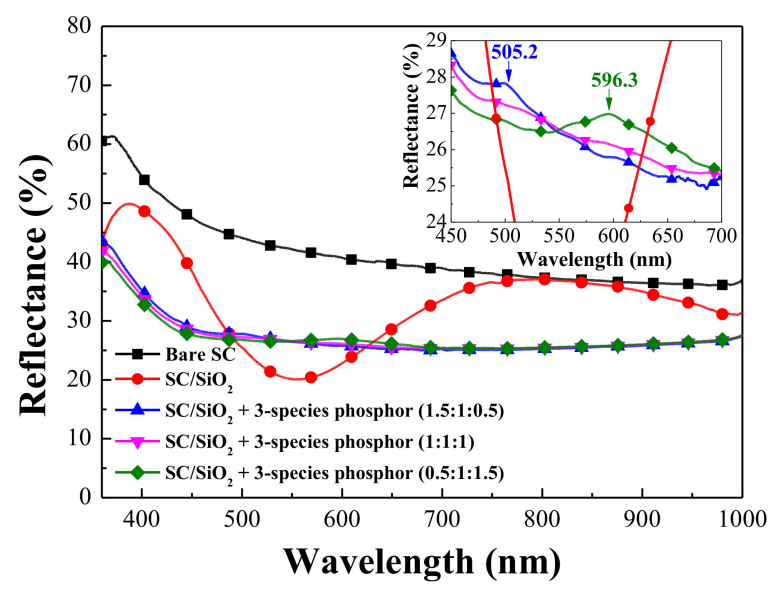

Figure 5. Reflectance spectra of bare silicon solar cell, cell coated with a 250-nm thick $\mathrm{SiO}_{2}$ layer, and cells coated with a $\mathrm{SiO}_{2}$ layer that included three species of Eu-doped phosphors in various weight ratios $(0.5: 1: 1.5$, or $1: 1: 1$, or $1.5: 1: 0.5$ in $w t \%)$.

Figure 6 presents the EQE response of the bare silicon solar cell, the cell coated with a 250-nm thick layer of $\mathrm{SiO}_{2}$, and cells coated with a $\mathrm{SiO}_{2}$ layer that included three species of Eu-doped phosphors in various weight ratios (0.5:1:1.5, or 1:1:1, or 1.5:1:0.5) (wt \%). The EQE values of the cell with a 250-nm thick $\mathrm{SiO}_{2}$ layer were elevated at wavelengths of 350-900 nm due to the anti-reflective properties of the $\mathrm{SiO}_{2}$ layer. A peak EQE response of $78 \%$ was obtained at a wavelength of $550 \mathrm{~nm}$, which is in 
good agreement with the optical reflectivity of the cell with only a $\mathrm{SiO}_{2}$ layer. The EQE response of cells with Eu-doped phosphors presented a broadband increase in EQE values from 350 to $1000 \mathrm{~nm}$, compared to that of the bare silicon cell. Thus, the EQE response of the cells with Eu-doped phosphors is also in good agreement with the optical reflectance values. At wavelengths of 350-450 nm, the EQE values of the cells with Eu-doped phosphors were higher than that of the cell with only a $\mathrm{SiO}_{2}$ layer. This can be attributed to the LDS effects of the Eu-doped phosphor particles. Incident photons with wavelengths between 350 and $450 \mathrm{~nm}$ were absorbed by Eu-doped phosphor particles and re-emitted as photons at visible wavelengths $(500-750 \mathrm{~nm})$. This allowed the emitted photons to be absorbed near the depletion region of the $\mathrm{p}-\mathrm{n}$ junction and also near the high responsivity band of the silicon solar cell. The resulting charge carriers provide higher photocurrent as well as higher collection efficiency. We also compared the average weighted EQE (EQE $\left.E_{W}\right)$ of cells from 380 to $450 \mathrm{~nm}$ and from 380 to $1000 \mathrm{~nm}$. The $E Q E_{W}$ results were calculated using Equation (2).

$$
E Q E_{w}=\frac{\int_{\lambda_{\min }}^{\lambda_{\max }} E Q E(\lambda) \cdot \phi_{p h}(\lambda) d \lambda}{\int_{\lambda_{\min }}^{\lambda_{\max }} \phi_{p h}(\lambda) d \lambda}
$$

where $E Q E(\lambda)$ is the $E Q E$ value as a function of wavelength and $\phi_{p h}(\lambda)$ is the photon flux of AM $1.5 \mathrm{G}$ solar energy spectrum as a function of wavelength. The $E Q E_{W}$ values are listed in Table 2. The EQE results demonstrate that the EQE of the 0.5:1:1.5 cell exceeded that of the 1:1:1 cell as well as that of the 1.5:1:0.5 cell. In addition, the EQE response of the cells with Eu-doped phosphors is in good agreement with the luminescence spectra of the respective phosphor mixtures.

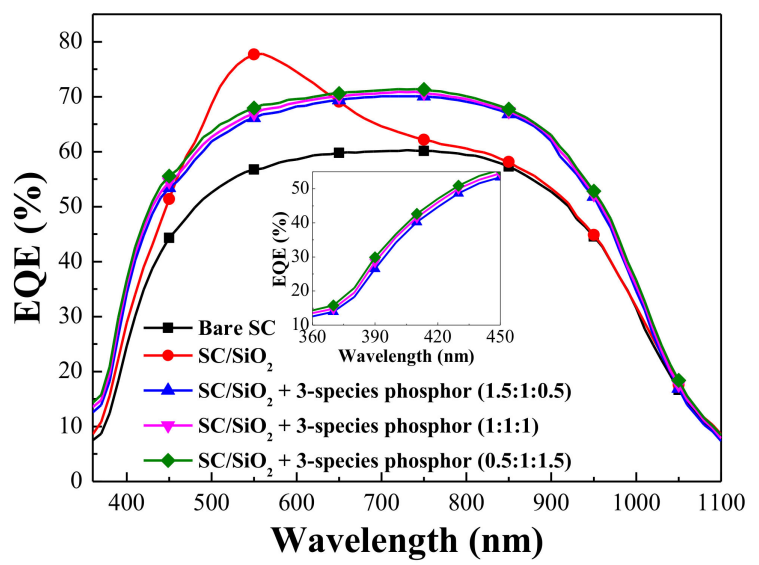

Figure 6. External quantum efficiency (EQE) response of bare silicon solar cell, cell coated with a 250-nm thick layer of $\mathrm{SiO}_{2}$, and cells coated with a $\mathrm{SiO}_{2}$ layer that included three species of Eu-doped phosphors at various weight ratios $(0.5: 1: 1.5$, or 1:1:1, or 1.5:1:0.5 in wt \%).

Table 2. Average weighted reflectance $\left(R_{W}\right)$ and average weighted EQE (EQEW) calculated for wavelengths from 380 to $450 \mathrm{~nm}$ and from 380 to $1000 \mathrm{~nm}$.

\begin{tabular}{|c|c|c|c|c|}
\hline Silicon Solar Cell & $\begin{array}{c}R_{W}(\%) \\
\text { @ } 380-450 \mathrm{~nm}\end{array}$ & $\begin{array}{c}R_{W}(\%) \\
@ 380-1000 \mathrm{~nm}\end{array}$ & $\begin{array}{c}\operatorname{EQE}_{W}(\%) \\
@ 380-450 \mathrm{~nm}\end{array}$ & $\begin{array}{c}\mathrm{EQE}_{W}(\%) \\
@ 380-1000 \mathrm{~nm}\end{array}$ \\
\hline Bare Solar Cell (SC) & 51.69 & 41.23 & 32.77 & 50.51 \\
\hline $\mathrm{SC} / \mathrm{SiO}_{2}$ & 45.03 & 31.69 & 37.58 & 58.09 \\
\hline $\mathrm{SC} / \mathrm{SiO}_{2}+3$-species phosphor (1.5:1:0.5) & 32.26 & 27.03 & 42.03 & 59.76 \\
\hline $\mathrm{SC} / \mathrm{SiO}_{2}+3$-species phosphor $(1: 1: 1)$ & 31.52 & 26.79 & 43.36 & 60.31 \\
\hline $\mathrm{SC} / \mathrm{SiO}_{2}+3$-species phosphor $(0.5: 1: 1.5)$ & 30.72 & 26.63 & 44.44 & 60.99 \\
\hline
\end{tabular}

Figure 7 presents the photovoltaic J-V curves of the bare silicon solar cell, the cell coated with a 250-nm thick layer of $\mathrm{SiO}_{2}$, and cells coated with a $\mathrm{SiO}_{2}$ layer that included three species of Eu-doped 
phosphor at various weight ratios (0.5:1:1.5, or 1:1:1, or 1.5:1:0.5 in wt \%). Table 3 details the photovoltaic performance of the cells. The short-circuit current density $\left(\mathrm{J}_{\mathrm{sc}}\right)$ and conversion efficiency $(\eta)$ of the $\mathrm{SiO}_{2}$-coated cell and the cells with Eu-doped phosphors were higher than those of the bare solar cell. The JSC of the cell with Eu-doped phosphors exceeded that of the cell with only $\mathrm{SiO}_{2}$, due to the additional LDS effects provided by forward-scattering by Eu-doped phosphor particles. The cell with Eu-doped phosphors (0.5:1:1.5 wt \%) presented $\mathrm{J}_{\mathrm{sc}}$ and $\eta$ enhancements $\left(\Delta \mathrm{J}_{\mathrm{sc}}, \Delta \eta\right)$ of $18.81 \%$ and $20.43 \%$ over the cell with a $\mathrm{SiO}_{2}$ layer. The cell with Eu-doped phosphors $(1: 1: 1 \mathrm{wt} \%)$ presented $\mathrm{J}_{\mathrm{sc}}$ and $\eta$ enhancements of $\left(\Delta \mathrm{J}_{\mathrm{sc}}=17.70 \%, \Delta \eta=19.67 \%\right)$. The cell with Eu-doped phosphors (1.5:1:0.5) presented $\mathrm{J}_{\mathrm{sc}}$ and $\eta$ enhancements of $\left(\Delta \mathrm{J}_{\mathrm{sc}}=16.27 \%, \Delta \eta=16.81 \%\right)$. The improvement in photovoltaic performance in the 0.5:1:1.5 cells exceeded that of all other cells due to the wide-band luminescent emission and re-emission of incident photons into the high responsivity band of the silicon solar cell. In addition, the $\mathrm{J}_{\mathrm{sc}}$ and $\eta$ enhancements of the cells with Eu-doped phosphors are also in good agreement with the EQE response of the respective phosphor mixtures. We are currently engaged in optimizing the ratio of Eu-doped phosphors in order to maximize photovoltaic performance.



Figure 7. Photovoltaic J-V curves of bare silicon solar cell, cell coated with 250-nm thick layer of pure $\mathrm{SiO}_{2}$, and cells coated with $\mathrm{SiO}_{2}$ layer that includes three species of Eu-doped phosphor at various weight ratios $(0.5: 1: 1.5$, or $1: 1: 1$, or 1.5:1:0.5 in wt \%).

Table 3. Detailed photovoltaic performances of bare solar cell, cell with layer of pure $\mathrm{SiO}_{2}$, and cells with $\mathrm{SiO}_{2}$ layer that includes three species of Eu-doped phosphor at various weight ratios (0.5:1:1.5, or $1: 1: 1$, or $1.5: 1: 0.5$ in wt $\%)$.

\begin{tabular}{|c|c|c|c|c|c|c|}
\hline Silicon Solar Cell & $\mathrm{V}_{\mathrm{oc}}(\mathrm{mV})$ & $\mathrm{J}_{\mathrm{sc}}\left(\mathrm{mA} / \mathrm{cm}^{2}\right)$ & Fill Factor (\%) & $\eta(\%)$ & $\Delta \mathrm{J}_{\mathrm{sc}}(\%)$ & $\Delta \eta(\%)$ \\
\hline Bare Solar Cell-1 (SC-1) & 518.4 & 24.56 & 73.45 & 9.35 & - & - \\
\hline $\mathrm{SC}-1 / \mathrm{SiO}_{2}$ & 522.2 & 27.71 & 73.54 & 10.64 & 12.83 & 13.80 \\
\hline Bare Solar Cell-2 (SC-2) & 518.1 & 24.39 & 73.47 & 9.28 & - & - \\
\hline Bare Solar Cell-3 (SC-3) & 517.8 & 24.47 & 73.04 & 9.25 & - & - \\
\hline $\mathrm{SC}-3 / \mathrm{SiO}_{2}+3$-species phosphor $(1: 1: 1)$ & 524.8 & 28.80 & 73.24 & 11.07 & 17.70 & 19.67 \\
\hline Bare Solar Cell-4 (SC-4) & 517.7 & 24.34 & 73.04 & 9.20 & - & - \\
\hline
\end{tabular}

\section{Conclusions}

This paper describes efforts to enhance the photovoltaic performance of solar cells by coating them with a layer of $\mathrm{SiO}_{2}$ that includes three species of Eu-doped phosphor particles at various weight ratios. Compared to the cell coated with a layer of pure $\mathrm{SiO}_{2}$, we observed significant improvements in cell efficiency due to an increase in short-circuit current density and open-circuit voltage. This is an indication that the improvement in photovoltaic performance was due to wide-band luminescent 
emission and the forward scattering by the Eu-doped phosphor particles. It can also be attributed to the fact that the emission band of the LDS layer matched the high responsivity band of the silicon semiconductor. Compared to the bare solar cell, the efficiency enhancement of the cell with a species ratio of $0.5: 1: 1.5 \mathrm{wt} \%(20.43 \%)$ exceeded that of the cell with a species ratio of $1: 1: 1 \mathrm{wt} \%(19.67 \%)$ and the cell with a species ratio of 1.5:1:0.5 (16.81\%).

Author Contributions: All of the authors conceived the experiments; W.J. designed, analyzed and wrote the first draft of the paper; B.J., J.J., and W.B. performed the experiments; H.J. and C.F. conducted EQE measurements; all authors contributed to the discussion.

Funding: This research was funded by the Ministry of Science and Technology of the Republic of China (Grant number: MOST 106-2221-E-027-101-MY3).

Acknowledgments: The authors would like to thank the Instrument Center, National Taipei University of Technology for EDS and PL measurements.

Conflicts of Interest: The authors declare no conflicts of interest.

\section{References}

1. Razykov, T.M.; Ferekides, C.S.; Morel, D.; Stefanakos, E.; Ullal, H.S.; Upadhyaya, H.M. Solar photovoltaic electricity: Current status and future prospects. Sol. Energy 2011, 85, 1580-1608. [CrossRef]

2. Parida, B.; Iniyan, S.; Goic, R. A review of solar photovoltaic technologies. Renew. Sustain. Energy Rev. 2011, 15, 1625-1636. [CrossRef]

3. Jäger-Waldau, A. PV Status Report 2017; JRC108105; Publications Office of the European Union: Luxembourg, 2017; Available online: https://www.researchgate.net/profile/Arnulf_Jaeger-Waldau/publication/ 321020820_PV_Status_Report_2017/links/5a08de1faca272ed279ff6c5/PV-Status-Report-2017.pdf (accessed on 27 April 2018).

4. Green, M.A. Silicon solar cells: The ultimate photovoltaic solution? Prog. Photovolt. Res. Appl. 1994, 2, 87-94. [CrossRef]

5. Couderc, R.; Amara, M.; Lemiti, M. In-depth analysis of heat generation in silicon solar cells. IEEE J. Photovolt. 2016, 6, 1123-1131. [CrossRef]

6. Rajesh, C.; Pramod, M.R.; Patil, S.; Mahamuni, S.; More, S.; Dusane, R.O.; Ghaisas, S.V. Reduction in surface recombination through hydrogen and 1-heptene passivated silicon nanocrystals film on silicon solar cells. Sol. Energy 2012, 86, 489-495. [CrossRef]

7. Belghachi, A. Detailed analysis of surface recombination in crystalline silicon solar cells. In Proceedings of the 2013 International Renewable and Sustainable Energy Conference (IRSEC), Ouarzazate, Morocco, 7-9 March 2013. [CrossRef]

8. Alharbi, F.H.; Kais, S. Theoretical limits of photovoltaics efficiency and possible improvements by intuitive approaches learned from photosynthesis and quantum coherence. Renew. Sustain. Energy Rev. 2015, 43, 1073-1089. [CrossRef]

9. Rühle, S. Tabulated values of the Shockley-Queisser limit for single junction solar cells. Sol. Energy 2016, 130, 139-147. [CrossRef]

10. Queisser, H.J. Detailed balance limit for solar cell efficiency. Mater. Sci. Eng. B Solid State Mater. Adv. Technol. 2009, 159-160, 322-328. [CrossRef]

11. Boriskina, S.V.; Chen, G. Exceeding the solar cell Shockley-Queisser limit via thermal up-conversion of low-energy photons. Opt. Commun. 2014, 314, 71-78. [CrossRef]

12. Huang, X.Y.; Wang, J.X.; Yu, D.C.; Ye, S.; Zhang, Q.Y.; Sun, X.W. Spectral conversion for solar cell efficiency enhancement using $\mathrm{YVO}_{4}: \mathrm{Bi}^{3+}, \mathrm{Ln}^{3+}(\mathrm{Ln}=\mathrm{Dy}, \mathrm{Er}, \mathrm{Ho}, \mathrm{Eu}, \mathrm{Sm}$, and $\mathrm{Yb})$ phosphors. J. Appl. Phys. 2011, 109, 113526-1-113526-7. [CrossRef]

13. Abrams, Z.R.; Niv, A.; Zhang, X. Solar energy enhancement using down-converting particles: A rigorous approach. J. Appl. Phys. 2011, 109, 114905-1-114905-9. [CrossRef]

14. Solodovnyk, A.; Forberich, K.; Stern, E.; Krč, J.; Topič, M.; Batentschuk, M.; Lipovšek, B.; Brabec, C.J. Highly transmissive luminescent down-shifting layers filled with phosphor particles for photovoltaics. Opt. Mater. Express 2015, 5, 1296-1305. [CrossRef] 
15. Lipovšek, B.; Solodovnyk, A.; Forberich, K.; Stern, E; Krč, J.; Brabec, C.J.; Topič, M. Optical model for simulation and optimization of luminescent down-shifting layers filled with phosphor particles for photovoltaics. Opt. Express 2015, 23, A882-A895. [CrossRef]

16. Gabr, A.M.; Walker, A.W.; Wilkins, M.M.; Kleiman, R.; Hinzer, K. Procedure to decouple reflectance and down-shifting effects in luminescent down-shifting enhanced photovoltaics. Opt. Express 2017, 25, A530-A538. [CrossRef] [PubMed]

17. Yu, Y.; Lan, L.; Cai, H. Integrating down-shifting and down-conversion into metal-organic frameworks to enhance the spectral conversion for solar cells. J. Phys. Chem. C 2018, 122, 96-104. [CrossRef]

18. Wang, C.Y.; Takeda, T.; Kate, O.M.; Xie, R.J.; Takahashi, K.; Hirosaki, N. Synthesis and photoluminescence properties of a phase pure green-emitting Eu doped JEM sialon $\left(\mathrm{LaSi}_{6-z} \mathrm{Al}_{1+\mathrm{z}} \mathrm{N}_{10-\mathrm{z}} \mathrm{O}_{\mathrm{z}}, \mathrm{z} \sim 1\right.$ ) phosphor with a large red-shift of emission and unusual thermal quenching behavior. J. Mater. Chem. C 2016, 4, 10358-10366. [CrossRef]

19. He, L.; Song, Z.; Jia, X.; Xia, Z.; Liu, Q. Control of luminescence in Eu ${ }^{2+}$-doped orthosilicate-orthophosphate phosphors by chainlike polyhedra and electronic structures. Inorg. Chem. 2018, 57, 609-616. [CrossRef] [PubMed]

20. Hung, W.B.; Chen, J.Y.; Sung, K.W.; Chen, T.M. Enhanced conversion efficiency of crystalline Si solar cells via luminescent down-shifting using $\mathrm{Ba}_{2} \mathrm{SiO}_{4}$ : $\mathrm{Eu}^{2+}$ phosphor. J. Ceram. Process. Res. 2014, 15, 157-161.

21. Lima, S.M.; da Cunha Andrade, L.H.; Silva, J.R.; Bento, A.C.; Baesso, M.L.; Sampaio, J.A.; de Oliveira Nunes, L.A.; Guyot, Y.; Boulon, G. Broad combined orange-red emissions from $\mathrm{Eu}^{2+}$ and $\mathrm{Eu}^{3+}$-doped low-silica calcium aluminosilicate glass. Opt. Express 2012, 20, 12658-12665. [CrossRef] [PubMed]

22. Chander, N.; Khan, A.F.; Chandrasekhar, P.S.; Thouti, E.; Swami, S.K.; Dutta, V.; Komarala, V.K. Reduced ultraviolet light induced degradation and enhanced light harvesting using $\mathrm{YVO}_{4}: \mathrm{Eu}^{3+}$ down-shifting nano-phosphor layer in organometal halide perovskite solar cells. Appl. Phys. Lett. 2014, 105, 033904-1-033904-5. [CrossRef]

23. Shehata, N.; Clavel, M.; Meehan, K.; Samir, E.; Gaballah, S.; Salah, M. Enhanced erbium-doped ceria nanostructure coating to improve solar cell performance. Materials 2015, 8, 7663-7672. [CrossRef] [PubMed]

24. Ho, W.J.; Yang, G.C.; Shen, Y.T.; Deng, Y.J. Improving efficiency of silicon solar cells using europium-doped silicate-phosphor layer by spin-on film coating. Appl. Surf. Sci. 2016, 365, 120-124. [CrossRef]

25. Ho, W.J.; Shen, Y.T.; Deng, Y.J.; Yeh, C.W.; Sue, R.S. Performance enhancement of planar silicon solar cells through utilization of two luminescent down-shifting Eu-doped phosphor species. Thin Solid Films 2016, 618, 141-145. [CrossRef]

26. Ho, W.J.; Shen, Y.T.; Liu, J.J.; You, B.J.; Ho, C.H. Enhancing photovoltaic performance using broadband luminescent down-shifting by combining multiple species of Eu-doped silicate phosphors. Nanomaterials 2017, 7, 340. [CrossRef] [PubMed] 